\title{
Study on the Influence of Cultural Conference and Exhibition Architectural Surface on the Architectural Design Style of Chinese Pavilion and Its Development
}

\author{
Yu Xiao \\ School of Fine Arts \\ Huanggang Normal University \\ Huanggang, China 438000
}

\begin{abstract}
Through the analysis of the design style of the exhibition hall surface and the humanistic philosophy, material structure, functional properties, texture structure and other characteristics it contains, the paper illustrates the important component of World Expo - pavilion, and the importance of the architectural surface as the carrier of spreading humanistic concept, the tendency of representing the inheritance of national culture, and the media communication function it plays, aiming to interpret the important inspiration significance of the design idea of the decoration style of architectural surface on the overall tendency of architectural culture, as well as its positive role in ideological exchange, regional humanities and global cultural diversity from some typical pavilions.
\end{abstract}

Keywords-exhibition building; humanistic inheritance; decoration style; material structure

\section{INTRODUCTION}

The global material resources, economic resources, cultural resources and political resources all survive and develop in integration. Everything is continuing to bear the "impact" of new things from all circles. They have been changed --- integrated --- evolved over the tide of times. The unique individuality is universally integrated. With the contradictions of entanglements and longing, and its own "uniqueness", every country expects its cultural achievements to be shine brilliantly on the stage of World Expo. They expect to maintain their independence and represent the historical originality among all countries of the world, but also hope to be accepted by more exotic cultures, so as to give full play to the influence. The design style publicizes and conveys the national regional humanistic features. The design of architectural surface tends to display the ancient and modern culture, science, technology, economic and agricultural achievements of the country to the world. According to the comprehensive strength of each country, different pavilions are designed to highlight the colorful national features.

\section{THE EXPRESSION STYLE OF ARCHITECTURAL SURFACE ART}

The design of architectural surface conveys the information of its own cultural characteristics. From the composition point of view, the pattern processing technique of the architectural surface is based on the combination of point, line and surface.

\section{A. Fine and Empty Art of "Point"}

Among hundreds of pavilions in the World Expo, the artistic hollowed-out style not only enriches the spatial level of the architectural surface and active the surrounding atmosphere, but also attracts the most attention from visitors from far. The profound and mysterious beauty inspired the visitor's strong curiosity. This design technique has always been favored by architectural designers.

The pavilions of French both in Shanghai and Milan World Expo were all designed in the form of displaying the natural landscapes abstractly that the landscapes of the country is designed as the architectural surface of the pavilion in hollowed-out style. In 2010 Shanghai World Expo, the architectural surface of French pavilion was the abstract shape of the sparkling Seine River. The golden lights reflecting on the waves are expressed by several downlights, and the Seine River, interwoven with light and shadow, was displayed by the concrete crossing grids. The romantic nature of French people was fully displayed in the design.

In 2015 Milan World Expo, French designer pushed this design technique to a new height that in addition to abstract the basic shape of the mountains, but also placed the hollowed-out model of the whole wooden structural truss upside down on the pavilion roof. The external layer of the architectural surface was hollow out enclosed by larch batten and the internal layer was spruce wood. Each interior hollowed-out stall was hung with the commodities from the famous local market Baltard Market. The design style is better than the previous one. The architectural surface of Polish pavilion in Shanghai World Expo was also in hollow 
out style. On the recycled plywood, one after another papercutting shape hollow out patterns were extraordinarily eyecatching under the inner lamplights. The plump shape, complex holes and warm colored surface made people feel warm, inclusive, active and lovely. The architectural surface of Italy pavilion in Milan World Expo was in a staggered shape, and the architectural surfaces of pavilions of Switzerland, Brazil, Turkey and Russia, etc. in Shanghai World Expo were all using hollow out technique.

\section{B. Dynamic Art of "Line"}

A number of pavilions in the World Expo were designed in the arc shape, which is a most commonly used surface shape in pavilion buildings. The arc surface of pavilions can best reflect the open style and random uncertainty, with the psychological suggestion of calling the visitors to be relaxed and open-minded. The typical representatives are Denmark and Australia pavilions in Shanghai World Expo and Vanke pavilion in Milan World Expo, etc. In Shanghai World Expo, the Danish pavilion uses its own architectural design to give people answers. A circling arc holds "the Gulf of Copenhagen" in its arms and gives the small Mermaid of the water infinite security. The surface of the building was made of curved steel plate, supported by steel frame. According to the different vertical load data, the hole in the steel plate varied its diameter and size in order to achieve the best equilibrium state. The Danish pavilion, bold and novel, and full of dynamic imagination, won great applause. People were affected by the healthy and positive urban life advocated by the Denmark, reflecting a fast-paced dynamic city, expressing its infinite vitality to life. It also told people that life is optimistic, positive, bold and fearless.

In 2015 Milan World Expo, there was a bright "red" that was especially attractive looking far away. It was the surface of "luxury gold color" Vanke pavilion, the glittering and shining "dragon scale". Each scale of the metal-like surface is different in color from different angle. The scale of the dragon is made of glazed pottery. The coatings are specially developed by foreign laboratories. The curved surface is like a giant dragon that is circling up. Although it was the pavilion of the enterprise, its ingenious design is not inferior to other national pavilions.

\section{Grand and Magnificent Bulk "Surface"}

"Steady, dependable and dignified" are the intuitive feelings that this kind of surface conveyed. If the light and varied hollow out surface can be regarded as the elegant "female", the bold and forthright bulk cutting surface is like the decisive "male", the deep strength and not messy characteristics were fully displayed. People are deeply influenced by this emotion by the Italy pavilion in 2010 Italy World Expo. Starting from a folk game, the transparent cement and glass curtain are neatly summed up in a box like a square. The neat cutting like the fine lines under the mechanists. The uniformed lines form the outside circle. As a whole, the traditional and conservative large model remains unchanged, while the sharp angle of the detail is hidden in the independence of individuality. The surface material is a newly developed kind — transparent cement.
This kind of environmentally friendly building materials, which embeds special resin materials into thick concrete slabs, can bring out indoor lighting at night, and create unique outdoor light environment at night. People who have seen transparent cement and Italy pavilion are infected by the character of the pursuit of classic extremes of the nation and the country.

Germany pavilion of the same year also showed its specialties of course. Using a rigorous mechanical operation, four special-shaped modules are erect on the ground with a small area of ground touch. In order to create the effect of bottom without foundations, the outer layer of the building was coated with PVC coated polyester fabric, and the inner layer was sandwich plate. As the building is translucent, the whole pavilion was wrapped in a dim and dreamy realm, which changed the stereotype of cold and rigid German people that they also have a gentle side, although this fantastic impression is completed in mechanical performance under extreme tolerance. Canada pavilion, Finland pavilion, Korea pavilion, and Romania pavilion of Shanghai World Expo also have the similar techniques. The "surface" cutting of large modules is also one of the designers' favorite design methods.

\section{Multi "Points", "Lines" and "Surface" Art}

The physical form features of nature, such as sound, light, color, shape and movement, are effectively refined and then used in the design. This kind of design often creates amazing visual effects beyond imagination, such as Britain pavilion, the United Arab Emirates pavilion in Shanghai World Expo, and Britain pavilion in Milan World Expo, etc. Britain pavilion have used this technique more than one time. The building was not large, with no complex traffic network inside, and the space function structure is relatively simple. Only from the big direction, through the vivid narrative of the theme, it expresses the human treasure of the various substances in nature, which is also the wonderful part that made it stand out from hundreds of pavilions. The "seed bank" of the Britain pavilion in World Expo, Shanghai, has become the focus of the world's report, and the lovely "Dandelion ball" has caused global attention. The surface of the exhibition hall consisted of a long acrylic long tube with a distance of about 10 centimeters. Tens of thousands of seeds were inserted into the seed pipe, imitating dandelion fluff effect and filling the building surface, forming a small wool ball object, standing on the land of two hundred square meters. The shock of visual impact surpassed all other pavilions. The building skin combined advanced technology and close structural design. As the key part of architecture, it carried the main design concepts expressed by architects, and conveyed the purpose of loving nature, cherishing nature and publicize the spirit of environmental protection. If "seed bank" was just a small climax of the bionic design in the UK, it reflected the Chinese and foreign designers' journey from concept creation to construction and implementation, and only let the world see a static effect. Then the "honeycomb" in World Expo, Milan, introduced a multidirectional effect, such as sound and electricity, and pushed the bionics design to the extreme. Many experts, such as acoustics, physicists, 
and bee experts and so on, have gathered the vibration rules in honeybee activity to reach thousands of LED lights through sensor processing. The lights flickered as the bees move and gather together to form a huge lamp ball, surrounded by a thick layer of aluminum frame. The architectural surface is still in the leading role. The designer intended to emphasize the contribution of bees to human beings and nature and the crisis they were facing, and arouse the public's attention to bees with strong visual impact. There is no doubt that the Britain pavilion, like the previous one, has caused a world attention once again.

\section{E. Slice "Surface" Style}

The design method can make the building surface appear complex, with arbitrary deformation and very strong plasticity. The process of assembling components is as interesting as game collage, and each piece is in strict order. In the right place, they have a very high "spirit of collaboration", both independent and integral part of the integration. The gorgeous piece of the surface of Spain pavilion in Shanghai World Expo started from an accident. The original idea of the designer is a smooth heteromorphy skin style, but it became a pattern of flaky combination because of the difficulty of construction.

The surface of Shanghai World Expo Spain Pavilion was a plate color shades of rattan, rustic yet gorgeous. From a historical point of view, the designer intended to pay tribute to its historic nature through the old vines weaving technology. From the anthropomorphic humanistic point of view, the rattan is soft and tough, like a simple mother, with a vicissitudes of faces, and gaze at you with emotional eyes, clearly interprets the "personification" image of the motherland in the mind of the designer. From the point of view of environmental protection, the rattan material is derived from nature, which can be recycled and green. The piece shaped surface of Spain pavilion was unique in World Expo, Shanghai, and its influence can be seen in the design of the skin texture of the Chinese Pavilion in World Expo, Milan. Without too many words, the design of the roof of the China pavilion in World Expo, Milan, and the outer layer are also piece shaped. It also used the original ecological environmental protection material, bamboo slices, imitating the wheat in the wind. According to the typical China style roof ridge top nine large collage undulating roof of great momentum. The inner layer of bamboo sheet is waterproof PVC film and load-bearing member. In terms of culture, China has great advantages, relying on five thousand years of culture, see how complicated and refining the process is, and taking the essence without losing it. The architectural surface style needs both cultural connotation and modern expressive technique. The final design of China pavilion was not disappointing in terms of culture, technology and practicality. Through modern and concise lines, a modern country with thousands of years of farming culture is presented to the world.

\section{SCIENCE AND TECHNOLOGY PROMOTE THE \\ PluRAlistic DEVElopMENT OF ARCHITECTURAL SURFACE, AND CONTINUE THE IMPLEMENTATION AND PRACTICE OF ENVIRONMENTAL PROTECTION CONCEPT}

Enlightenment of open Pavilion space makes us know better to the building function of the exhibition hall. There is unified space with a roof, can withstand the greatest impact of human flow, the most visual angle, is a successful exhibition building. Building with no outside layers has the condition of being "baptized" this way. The pavilion of New Zealand in World Expo, Shanghai, was presented to the world this way. Open for all sides and only with a roof. Flowers and plants, mountains of their unique natural landscape were presented with 360 degree hassle way under the roof. The roof, like a folded paper, expanded its mind to the greatest extent to meet the people around them. When the equivalent transformation is converted into a qualitative change, there is the demand for "greatly discerning and apprehending". Herzog has his own understanding and appeal for World Expo. The slow food restaurant in Milan World Expo was the true embodiment of this demand, and it also yearned for people's understanding of this idea. A simple, sloping roof with several bearing columns and the middle open space is divided by tables and chairs. The whole architectural design style was concise yet not simple. Building materials are mainly wood. After the Expo, it can be recycled. It fully reflected Herzog's design idea of throwing away the luxury and pursuing the intrinsic functions of the building.

World Expo provides a platform for the exchange of science and technology and economy for all countries, not only achieve economic income, attract tourists, stimulate consumption, but also realize the long-term development goal of scientific and technological exchange and economic and trade cooperation. It has strengthened the exchange of culture, science and technology in all the countries of the world, and brought the "mysterious and cold" new technology to the common people. The "Crystal Palace" of Britain in the first World Expo was mainly made of steel and glass. The transparent wall has aroused the attention of the world, and the technology and efficiency it covered is exhilarating. Since then, the surface of pavilion has become an indispensable spot. In 2000 World Expo, Japanese architect Sakamoto brought his "paper" building, since this new building made great contribution to the world, he won the award for architecture prize. In 2010 Shanghai World Expo, the transparent cement, new antibacterial floor and recyclable crop extract and decoration materials were all the technological inventions that make the earth more environmentally friendly and healthier and healthier for human life. People feel that high technology is so close to them. 2015 Italy World Expo also brought new developed biodynamic concrete materials that can effectively degrade the harmful ingredients in haze. Austria has also brought their urban building "forest" microclimate green concept. The new solar cell can generate electricity from all light energy such as sunlight and artificial light. These are all the high level things that are closely related to ordinary life. 
World Expos over the past years have all put forward a theme related to the healthy development of human beings. For example, the 1974 Spokane World Expo, USA, proposed "Pollution-Free Progress; 1990 Japan Osaka World Expo "Human and Nature"; 2010 Milan Expo "Feed the Earth: the Energy of Life"; and 2000 German Hanoverian Expo "Human-Nature-Science and Technology-Development"; these have all brought the positive and active environmental concept to the society. At the same time, the organizers and exhibitors carried out these ideas through real science and technology. People do not think that is empty talk, nor is it a "false sky". Instead, they see people from all walks of life, using their labor wisdom to actively solve the problems faced by mankind, and contribute their wisdom to the harmonious coexistence of the earth and mankind.

\section{CONCLUSION}

As the birthplace of the Chinese nation with a history of thousands of years, Shanghai, China, as a sponsor of World Expo in 2010, has expressed a climax to realize the importance of the World Expo. From the planning to the implementation, its size was grand and the design of the pavilions was exquisite, and the people of all walks of life were actively cooperating with each other. China has provided favorable geographical conditions and preferential treatment for all countries, so that designers from different countries can give full play to their own pavilions, especially the Chinese pavilion. Milan World Expo has witnessed several creative pavilions that contain local cultural elements and high and new technology, such as the British hive, French mountain landforms, Chinese undulating, Austria forest plants, and so on. Because these are all "irregularities", it was a great pity for a group of people who are eager to understand advanced technology and multiculturalism. At least, what people see in the World Expo is much more wonderful than imagination. Let people accept new things and old things at the same time with open arms. It is just as well for people to expand their visions and also stimulate economy.

\section{ACKNOWLEDGMENT}

This paper is done on the basis of "On the Influence of Cultural Conference and Exhibition Architectural Surface on the Architectural Design Style of Chinese Pavilion and its Development", project (No.: 15Q230) of disciplinary construction of Huanggang Normal University, 2015 the Education Department of Hubei Province youth research project. Sincerely thanks!

\section{REFERENCES}

[1] Lian Ailan. Illustrations of Western Architectural Art [M]. Shanghai: Shanghai Joint Publishing, 2008.

[2] The Death and Life of Great American Cities [M]. Beijing: Yilin Translation Publishing House, 2006.

[3] Dong Jianhong. History of Urban Construction in China [M]. Beijing: China Architecture \& Building Press, 2004.

[4] Wang Xieyan. Interpretation of Chinese Architectural Ornaments [M]. Mechanical Industry Press, 2007.
[5] Li Baofeng, Li Gang. Architectural Surface — Study on the Design of Architectural Surface in Hot Summer and Cold Winter Area [M]. China Architecture \& Building Press, 2010.

[6] Architectural Detail [M]. Dalian: Dalian University of Technology Press, 2015: 495 630

[7] Journal of Architecture [M]. Beijing: Architectural Society of China, 2015: $16 \sim 57$

[8] Journal of Architecture [M]. Beijing: Architectural Society of China, 2008: $1 \sim 132$ 